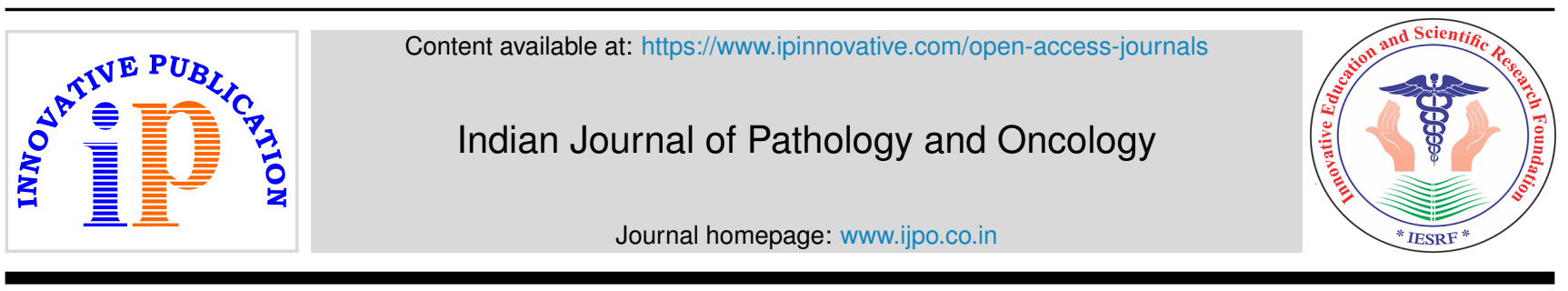

\title{
Editorial
}

\section{Atypical chronic myeloid leukemia: A brief overview}

\author{
Iffat Jamal ${ }^{1, *}$ \\ ${ }^{1}$ Dept. of Hematology, Indira Gandhi Institute of Medical Sciences, Patna, Bihar, India
}

\section{A R T I C L E I N F O}

Article history:

Received 20-12-2020

Accepted 26-12-2020

Available online 20-02-2021
(C) This is an open access article distributed under the terms of the Creative Commons Attribution License (https://creativecommons.org/licenses/by/4.0/) which permits unrestricted use, distribution, and reproduction in any medium, provided the original author and source are credited.
Atypical chronic myeloid leukemia is a clonal hematopoietic disorder characterized by both dysplastic and proliferative features, including persistent granulocytosis with left shift, bone marrow hypercellularity with dysplastic hematopoiesis, and myeloid preponderance; aCML is a disorder of older adults with apparently no sex predominance. ${ }^{1}$

aCML is a rare myeloid neoplasm with an incidence of 1-2 cases for every 100 cases of Philadelphiapositive CML. Clinical manifestations, similar to those of myeloproliferative syndrom, are related to anemia, thrombocytopenia, and splenomegaly. The etiology and pathogenesis of aCML are not known. The 2016 WHO diagnostic criteria for aCML relies on:

1. Peripheral blood leukocytosis (WBC $\geq 13 \times 10^{9} / \mathrm{L}$ ) due to increased number of neutrophils and their precursors $\geq 10 \%$.

2. Dysgranulopoiesis (abnormal chromatin clumbing).

3. Basophils $<2 \%$ of leukocytes, No or minimal absolute basophilia.

4. Monocytes $<10 \%$ of leukocytes, No or minimal absolute monocytosis.

5. Hypercellular BM with granulocytic proliferation and granulocytic, dysplasia, with or without dysplasia in the erythroid and megakaryocytic lineages.

6. $<20 \%$ blasts in the blood and BM.

\footnotetext{
* Corresponding author.

E-mail address: iffatjamal111@gmail.com (I. Jamal).
}

7. No Philadelphia chromosome or BCR-ABL fusion gene.

8. No rearrangement of PDGFRA, PDGFRB, FGFR1 rearrangement or JAK2.

The most common karyotypic changes reported in aCML include trisomy 8 and del (20q), abnormalities involving other chromosomes such as 12, 13, 14, 17, 19 and 21 have also been described. ${ }^{2-4}$

The etiology and pathogenesis of aCML are not known, many gene mutations have been found in aCML, such as, NRAS/KRAS (33\% patients), TET2 (33\% patients) CBL (10\% patients), E2H2 (13\% patients) and SETBP1 (25\% patients) and so on. ${ }^{5}$ The syndrome of abnormal chromatin clumping, which has long been recognized as representing a hematologic neoplasm with both myelodysplastic and myeloproliferative features is, in most cases, simply a morphologic variant of aCML; the risk of leukemic transformation is approximately $30 \% .^{6}$ The majority of patients die of BM failure. ${ }^{7}$

Atypical CML patients showed poor prognosis when treated with conventional chemotherapy, the median survival is only 24 to 25 months. ${ }^{8}$ A retrospective study in MD Anderson Cancer Center found that: Age ( $>65$ years), anemia (hemoglobin $<10 \mathrm{~g} / \mathrm{dL}$ ), white blood cell count $\left(\mathrm{WBC}>50 \times 10^{9} / \mathrm{L}\right)$ are three independent factors in aCML. ${ }^{8,9}$

Treatment options such as AML induction type chemotherapy followed by an allogeneic stem cell 
transplantation are an option for only a minority of patients, but are the only modality that offers a cure.

\section{Conclusion}

In aCML is difficult to distinguish from other subtypes of MPS (CML, CNL and CMML), which is easy to misdiagnosis clinically. The presence of a granulocytic proliferation associated with marked dysgranulopoiesis and the absence of BCR-ABL1 translocation are the defining features of aCML.

\section{Conflict of Interest}

None.

\section{References}

1. Cazzola M, Malcovati L, Invernizzi $R$. Myelodysplastic/Myeloproliferative Neoplasms. Hematol.

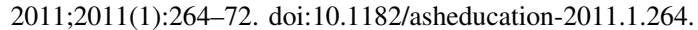

2. Faramarz N. Massachusetts: Atlas of Hematopathology Morphology, Immunophenotype, Cytogenetics, and Molecular Approaches. Cambridge: Academic presse; 2013.

3. Arber DA, Orazi A, Hasserjian R, Thiele J, Borowitz MJ, Beau ML. The 2016 revision to the World Health Organization classification of myeloid neoplasms and acute leukemia. Blood. 2016;127(20):2391-

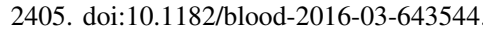

4. Efferi A, Gilliland G. Classification of chronic myeloid disorders: from Dameshek towards a semi-molecular system. Best Pract Res Clin Haematol. 2006;19(3):365-385.

5. Piazza R, Valletta S, Winkelmann N, Redaelli S, Spinelli R, Pirola A, et al. P-027 Recurrent SETBP1 mutations in atypical chronic myeloid

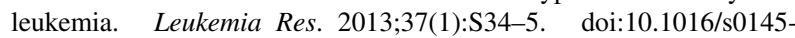
2126(13)70076-6.

6. Czader M, Orazi A. Blood and Bone Marrow Pathology. London: Churchill Livingstone; 2011.

7. Onida F, Ball G, Kantarjian HM, Smith TL, Glassman A, Albitar M, et al. Characteristics and outcome of patients with Philadelphia chromosome negative,bcr/abl negative chronic myelogenous leukemia. Cancer. 2002;95(8):1673-84. 601:10.1002/cncr.10832.

8. Koldehoff M, Beelen DW, Trenschel R, Steckel NK, Peceny $\mathrm{R}$, Ditschkowski $\mathrm{M}$, et al. Outcome of hematopoietic stem cell transplantation in patients with atypical chronic myeloid leukemia. Bone Marrow Transplant. 2004;34(12):1047-50. doi:10.1038/sj.bmt.1704686.

9. Kaminskas E, Farrell AT, Wang YC, Sridhara R, Pazdur R. FDA drug approval summary: azacitidine (5-azacytidine, Vidaza) for injectable suspension. Oncologist. 2005;10(3):176-82. do1:10.1634/theoncologist.10-3-176.

\section{Author biography}

Iffat Jamal, Assistant Professor

Cite this article: Jamal I. Atypical chronic myeloid leukemia: A brief overview. Indian J Pathol Oncol 2021;8(1):3-4. 